\title{
Study in synthesis and characterization of carbon nanotubes decorated by magnetic iron oxide nanoparticles
}

\author{
Hamidreza Sadegh • Ramin Shahryari-ghoshekandi • \\ Maryam Kazemi
}

Received: 11 July 2014/Accepted: 24 September 2014/Published online: 9 October 2014

(C) The Author(s) 2014. This article is published with open access at Springerlink.com

\begin{abstract}
Magnetic nanoparticles iron oxide with average sizes of $6 \mathrm{~nm}$ were synthesized by a chemical coprecipitation method from mixtures of $\mathrm{FeCl}_{2} \cdot 4 \mathrm{H}_{2} \mathrm{O}$ and $\mathrm{FeCl}_{3}$ $6 \mathrm{H}_{2} \mathrm{O}$. For preparation, multi-walled carbon nanotubes (MWCNTS) with outer diameter of $50 \mathrm{~nm}$, wall thickness from 1 to $2 \mathrm{~nm}$ and length from 500-2,000 nm were used. Characterization of the $\mathrm{MWCNT}-\mathrm{Fe}_{3} \mathrm{O}_{4}$ by X-ray powder diffraction (XRD), Fourier transform infrared (FTIR) spectroscopy, scanning electron microscope (SEM), transmission electron microscope (TEM), thermo-gravimetric analysis (TGA) and magnetic characterization was conducted on a vibrating sample magnetometer (VSM).
\end{abstract}

Keywords Carbon nanotube - Magnetic nanoparticles . Nanocomposite $\cdot$ Multi-walled carbon nanotubes

\section{Introduction}

Since discovery of their structures in 1991 [1], carbon nanotubes (CNTs) have attracted considerable interdisciplinary interest because of their unique physical and chemical properties; however, the hydrophobicity of CNTs may limit their application [2, 3]. Therefore, surface modification of CNTs with functional groups and/or

H. Sadegh $(\bowtie) \cdot$ R. Shahryari-ghoshekandi

Department of Chemistry, Science and Research Branch, Islamic

Azad University, Tehran, Iran

e-mail: h.sadegh@chemist.com

R. Shahryari-ghoshekandi

e-mail: r.shahreyari@chemist.com

M. Kazemi

Department of Chemistry, Payame Noor University, Zanjan, Iran e-mail: maryamkazemi691026@gmail.com nanoparticles so as to disperse them into aqueous solutions becomes a key step for their applications [4].

Magnetic nanoparticles are gaining importance as they can be used as highly effective, efficient and economicallyviable adsorbents, with the additional advantage of their easy separation under a magnetic field for reuse [5].

Herein, we describe a very simple, direct, and effective approach for the decoration of multi-walled carbon nanotubes (MWCNTs) by $\mathrm{Fe}_{3} \mathrm{O}_{4}$ magnetic nanoparticles. Our results suggest a novel and simple approach for controlling the size and size distribution of $\mathrm{Fe}_{3} \mathrm{O}_{4}$ on the surface of MWCNTs, which leads to a further development of CNTbased nanomaterials.

\section{Experimental}

Material

MWCNTs were purchased from NanoAmor Nanostructured \& Amorphous Materials, Inc, USA [Purity $>95 \%$, outer $>50 \mathrm{~nm}$, length 500-2,000 nm, surface area $\sim 40 \mathrm{~m}^{2} / \mathrm{g}$, and manufacturing method catalytic chemical vapor deposition (CVD)]. Other chemicals were purchased from Merck Inc, USA.

\section{Instrumentation}

X-ray powder diffraction (XRD) analysis was conducted on a Rigaku Smart Lab Diffractometer operated at $40 \mathrm{kV}$ and $35 \mathrm{~mA}$ using $\mathrm{Cu} \mathrm{K} \alpha$ radiation.

The characteristics of the $\mathrm{MWCNT}-\mathrm{Fe}_{3} \mathrm{O}_{4}$ were analyzed by attenuated total reflection-Fourier transform infrared spectrometer (100 spectra accumulation, $2 \mathrm{~cm}^{-1}$ resolution, BOMEM, Canada). FTIR samples were 


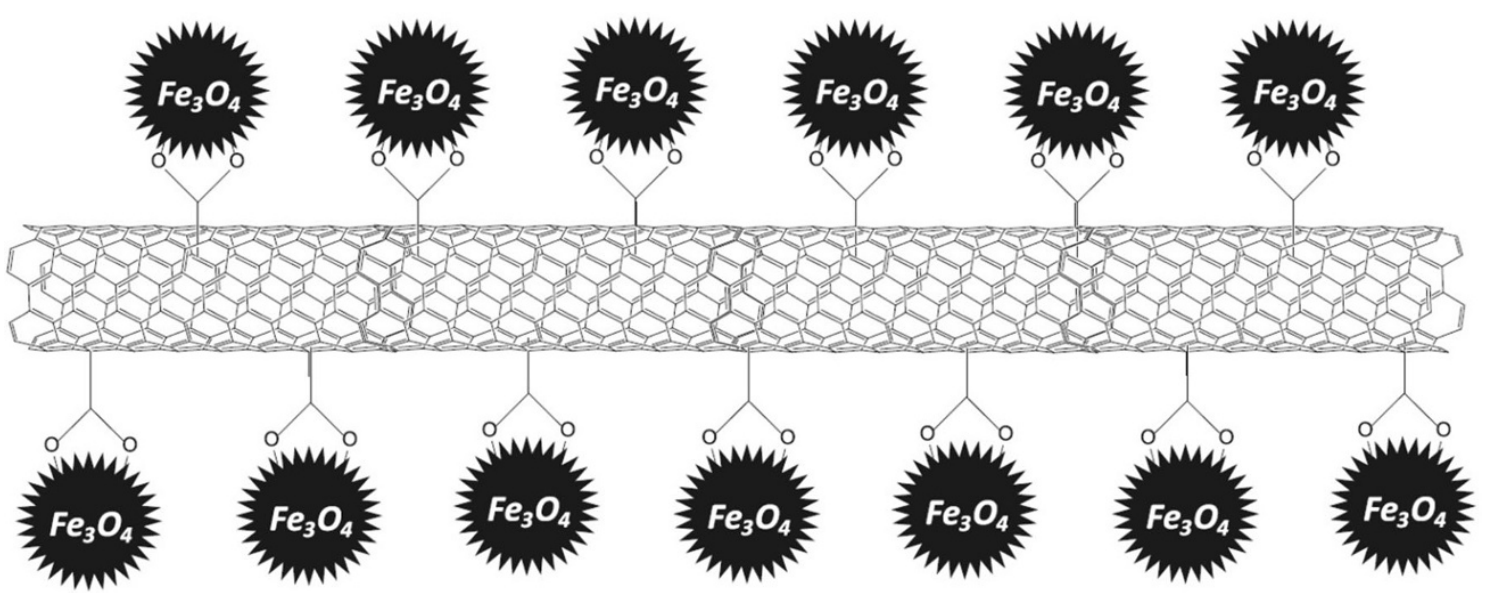

Fig. 1 Illustration of MWCNT-Fe $3 \mathrm{O}_{4}$

prepared by grinding dried MWCNTs and MWCNT- $\mathrm{Fe}_{3} \mathrm{O}_{4}$ together with potassium bromide $(\mathrm{KBr})$ to make a pellet that was dried in an oven for $8 \mathrm{~h}$ before the test.

A morphological analysis was carried out using a scanning electron microscope (SEM), (TESCAN, VEGA 3, USA).

Transmission electron microscopy (TEM) analysis was performed using a JEOL JEM microscope (TEM, JEOL 2010, Japan) operating at $200 \mathrm{kV}$ by depositing sample onto the lacey carbon-coated copper grids.

Thermo-gravimetric analysis (TGA) of all samples was done using SDT Q600 instrument from TA instrument. The temperature ranged from 25 to $1,000{ }^{\circ} \mathrm{C}$ and the heating rate was $10{ }^{\circ} \mathrm{C} / \mathrm{min}$.

Magnetic characterization was conducted on a vibrating sample magnetometer (VSM) (PPMS VSM, Model 6000).

Synthesis of MWCNT- $-\mathrm{Fe}_{3} \mathrm{O}_{4}$

Iron oxide nanoparticles were firstly synthesized by chemical coprecipitation according to the method reported with a minor modification $[6,7]$.

Typically, $\mathrm{FeCl}_{2} \cdot 4 \mathrm{H}_{2} \mathrm{O}$ and $\mathrm{FeCl}_{3} \cdot 6 \mathrm{H}_{2} \mathrm{O}$ with a molar ratio of 1:2 were mixed in deionized water. Afterwards, $10 \mathrm{~mL}$ of $2 \mathrm{~mol} / \mathrm{L} \mathrm{HCl}$ was added. The solution was heated to $30{ }^{\circ} \mathrm{C}$, under nitrogen protection with vigorous stirring. The as-formed solution was stirred at $30{ }^{\circ} \mathrm{C}$ at a constant $\mathrm{pH}$ value of $9\left(\mathrm{NH}_{3} \cdot \mathrm{H}_{2} \mathrm{O}\right.$ was used to adjust $\mathrm{pH}$ value) for $1 \mathrm{~h}$. The obtained precipitates were continuously mixed under constant heating at $50{ }^{\circ} \mathrm{C}$ for $30 \mathrm{~min}$. After cooling to room temperature, the obtained magnetic nanoparticles (denoted as $6 \mathrm{~nm} \mathrm{Fe}_{3} \mathrm{O}_{4}$ ) were several times washed with water and ethanol, ultrasonicated for $30 \mathrm{~min}$, and then dried under vacuum at $60{ }^{\circ} \mathrm{C}$ overnight.

The typical procedure for the preparation of MWCNT$\mathrm{Fe}_{3} \mathrm{O}_{4}$ was as follows: $3 \mathrm{~g}$ MWCNTs was dispersed into (a)

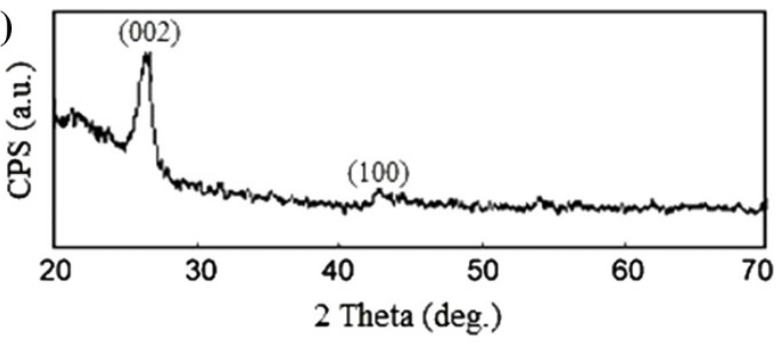

(b)

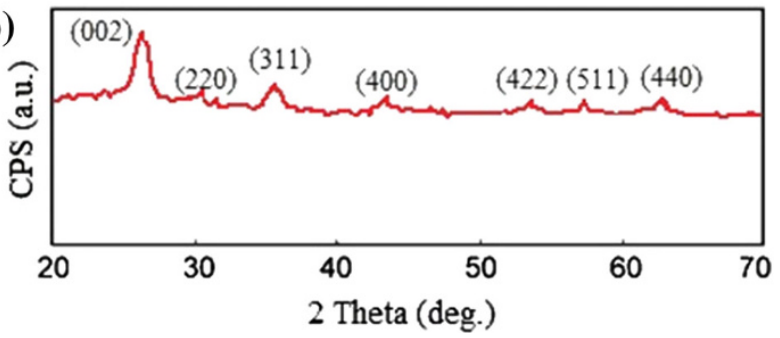

Fig. 2 XRD powder pattern of a MWCNT-COOH and $\mathbf{b}$ MWCNT$\mathrm{Fe}_{3} \mathrm{O}_{4}$

$150 \mathrm{~mL}$ of concentrated $\mathrm{HNO}_{3}$ ( $37 \%$ by mass fraction), followed by oil bath heating at $110{ }^{\circ} \mathrm{C}$ for $5 \mathrm{~h}[8,9]$. The solution was diluted by deionized water until the $\mathrm{pH}$ value of the filtrate was around 7. Such treatment decorated $-\mathrm{OH}$ and $-\mathrm{COOH}$ groups onto the surface of MWCNT, which was confirmed by infrared spectrum analysis. After further rinsing and drying, $200 \mathrm{mg}$ acidpurified nanotubes and $50 \mathrm{mg} \mathrm{Fe}_{3} \mathrm{O}_{4}$ nanoparticles were dispersed in $40 \mathrm{~mL}$ solution of deionized water/ethanol (1:1, volume ratio). The mixture was ultrasonicated for $1 \mathrm{~h}$ and then stirred at room temperature for $96 \mathrm{~h}$. The solution was separated from the residue using $200 \mathrm{~nm}$ filter membrane, followed by vacuum drying at $50{ }^{\circ} \mathrm{C}$ for $16 \mathrm{~h}$. A simplified scheme of MWCNT- $-\mathrm{Fe}_{3} \mathrm{O}_{4}$ is illustrated in Fig. 1. 
Fig. 3 FT-IR spectrum of a MWCNT-COOH and b MWCNT- $-\mathrm{Fe}_{3} \mathrm{O}_{4}$ (a)

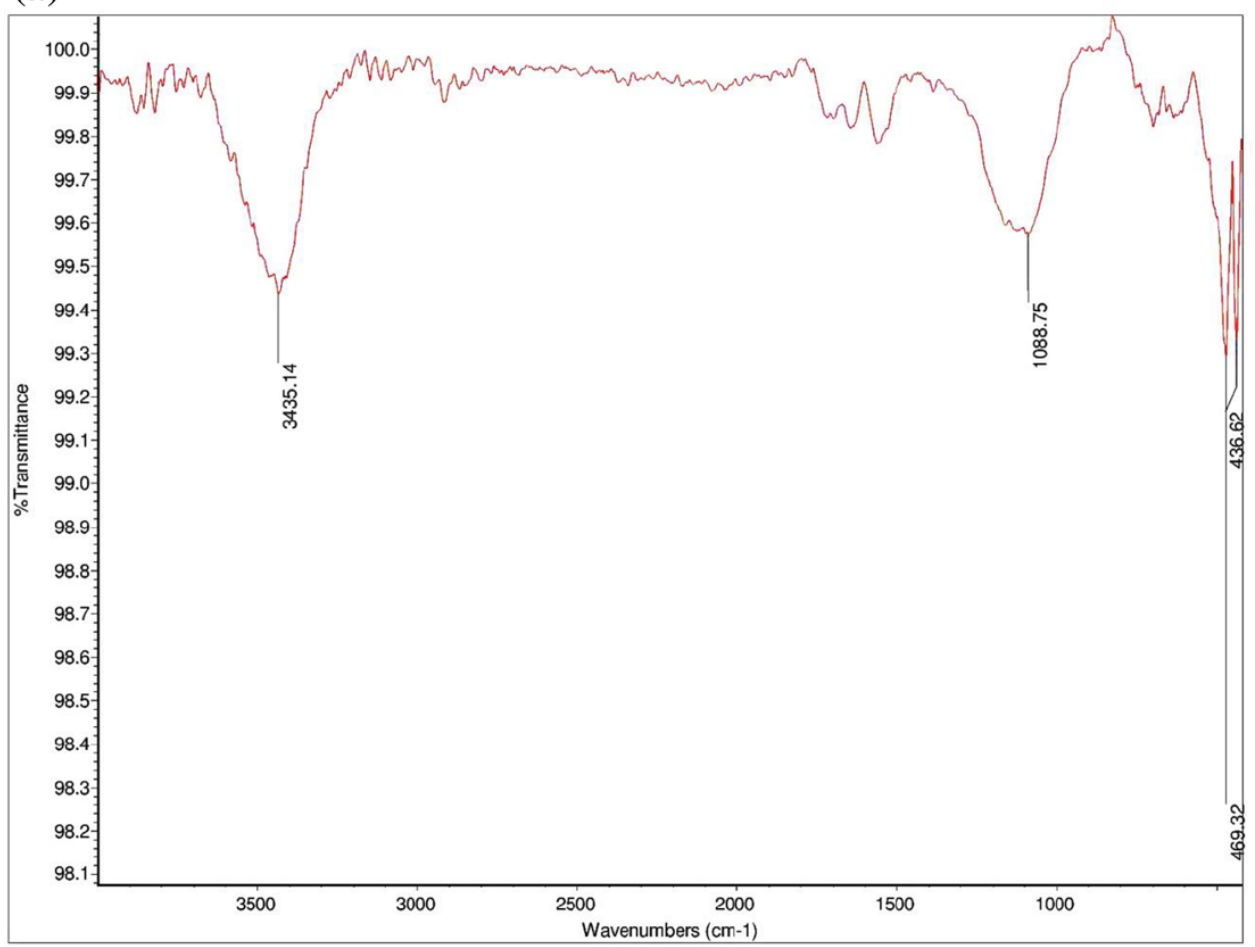

(b)

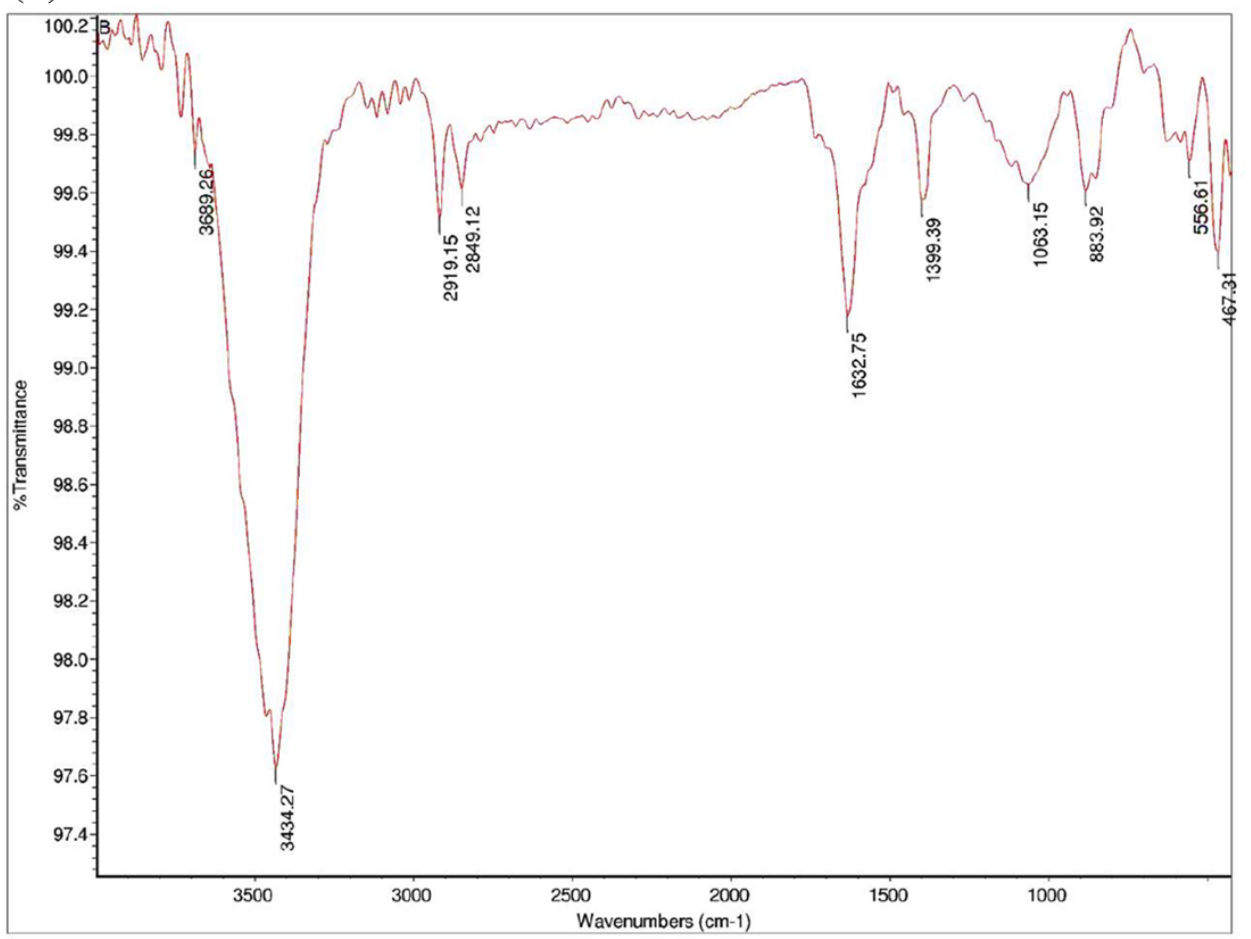




\section{Results and discussion}

XRD analysis

XRD powder patterns of MWCNT-COOH and MWCN$\mathrm{Fe}_{3} \mathrm{O}_{4}$ hybrid are shown in Fig. $2 \mathrm{a}$ and $\mathrm{b}$ respectively. The diffraction peaks at 2theta of 26,088 and 43,088 are attributed to the graphite structure (002) and (100) planes of the MWCNTs [10] in Fig. 2a, b showing that the hybrid is composed of two phases: cubic $\mathrm{Fe}_{3} \mathrm{O}_{4}$ and MWCNTs. No obvious peaks from other phases were observed [11]. The main peaks of $\mathrm{Fe}_{3} \mathrm{O}_{4}$ in the XRD pattern are broadened, indicating the smaller crystallite size of $\mathrm{Fe}_{3} \mathrm{O}_{4} \mathrm{NPs}$ [10]. The mean size of the crystallites of $\mathrm{Fe}_{3} \mathrm{O}_{4}$ in the MWCNT- $-\mathrm{Fe}_{3} \mathrm{O}_{4}$ (assuming spherical morphology) was estimated as $9 \pm 3 \mathrm{~nm}$ from the diffraction pattern by $\mathrm{X}$-ray line profile fitting [11].

\section{FTIR analysis}

The FTIR spectra of the samples are shown in Fig. 3. The band observed near $1,580 \mathrm{~cm}^{-1}$ in all samples shows the presence of the cylinder like carbon structure (rolled graphene sheet). According to Jishi et al. [12], several infrared active modes may have a wavenumber near $1,580 \mathrm{~cm}^{-1}$, while the wavenumbers depend on the geometry of the CNT. Besides, infrared wavenumbers are dependent on the nanotube diameter. The broadness of the band observed at $1,580 \mathrm{~cm}^{-1}$ for SWCNT samples can be explained by the polydispersity in the geometry of nanotubes. The stretching $\mathrm{C}=\mathrm{O}$ vibration of the carboxyl $(\mathrm{COOH})$ group is visible in the spectra of the modified carbon nanotubes. It was also observed at $1,713 \mathrm{~cm}^{-1}$ for MWCNT-COOH, and at $1,724 \mathrm{~cm}^{-1}$ for MWCNT- $\mathrm{Fe}_{3} \mathrm{O}_{4}$. Compared to MWCNT-COOH, this band reduced in the spectrum of MWCNT- $\mathrm{Fe}_{3} \mathrm{O}_{4}$. This reduction was ascribed to the linkage between magnetite particles and nanotubes, which was formed by a reaction of carboxyl groups with the surface of magnetite particles [13]. In the spectra of MWCNT $-\mathrm{Fe}_{3} \mathrm{O}_{4}$, the broadband around ca. $585 \mathrm{~cm}^{-1}$ showed the presence of iron oxide, primarily magnetite [13].

\section{TEM analysis}

As shown in Fig. 4, the morphologies of the samples were observed by TEM.

Figure 4 depicts an entangled network of acidified MWCNTs, which are attached to clusters of iron oxides. The iron oxide nanoparticle aggregates were composed of even smaller subunits of about $10 \mathrm{~nm}$ [14], implying that large particles may be formed via precipitation followed by a step-like aggregation process. In Fig. 4, MWCNTs are

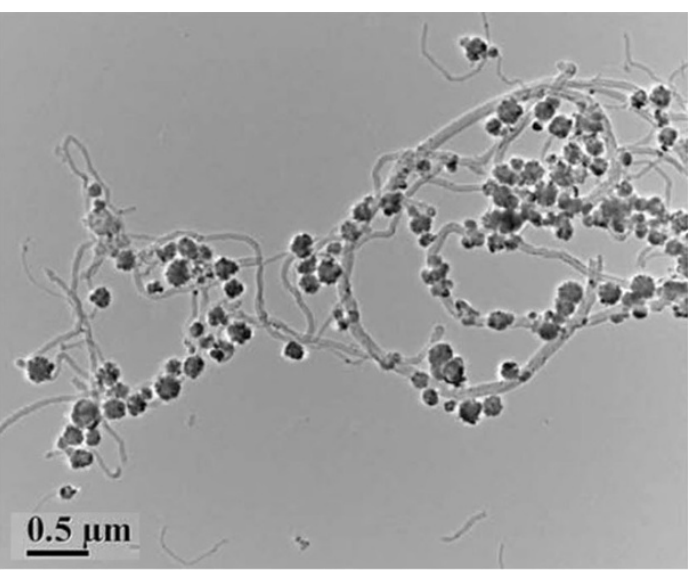

Fig. 4 Representative TEM images of MWCNT- $\mathrm{Fe}_{3} \mathrm{O}_{4}$ composites

covered with the carboxylic acid $(\mathrm{COOH})$ component in which iron oxide nanoparticles were uniformly dispersed without obvious aggregation. The carboxylic acid component grafted on the surface of the MWCNT was not destroyed in the process of loading iron oxides. Carboxylic acid can form complexes with metal ions because of their high number of coordinating functional groups [15]. This Figure shows representative TEM images of the MWCNT$\mathrm{Fe}_{3} \mathrm{O}_{4}$ nanocomposites.

\section{SEM analysis}

Scanning electron microscopy shown in Fig. 5 is the typical morphology of the MWCNT-COOH (Fig. 5a), and MWCNT- $-\mathrm{Fe}_{3} \mathrm{O}_{4}$ (Fig. 5b, c). SEM image (Fig. 5b, c) of the composites depicts an entangled network of oxidized MWCNTs (MWCNT-COOH) with clusters of iron oxides attached to them. The Surface area of the prepared composite was measured using BET method. The specific surface area of MWCNT- $\mathrm{Fe}_{3} \mathrm{O}_{4}$ composite was $92 \mathrm{~m}^{2} / \mathrm{g}$. Under the reaction conditions employed, four iron oxides are commonly formed. These are $\mathrm{Fe}_{3} \mathrm{O}_{4}$ (magnetite), $\gamma$ $\mathrm{Fe}_{2} \mathrm{O}_{3}$ (maghemite), $\alpha-\mathrm{Fe}_{2} \mathrm{O}_{3}$ (hematite) and $\alpha-\mathrm{FeO}(\mathrm{OH})$ (goethite). Among them, two magnetite and maghemite are magnetic [16]. Most of the nanoparticles formed showed a tendency to congregate. Similar results were reported by Fan and Li [13].

\section{TGA}

TGA was used to characterize the iron oxide content in the as-obtained composites. For the iron oxide sample (Fig. 6c), the weight increase at the broad temperature is attributable to the oxidation of the $\mathrm{Fe}_{3} \mathrm{O}_{4}$ into $\mathrm{Fe}_{2} \mathrm{O}_{3}$. The TGA curve of MWCNTs (Fig. 6a) shows a small mass loss at lower temperature because of the removal of absorbed water and the functional groups. An obvious weight loss in 


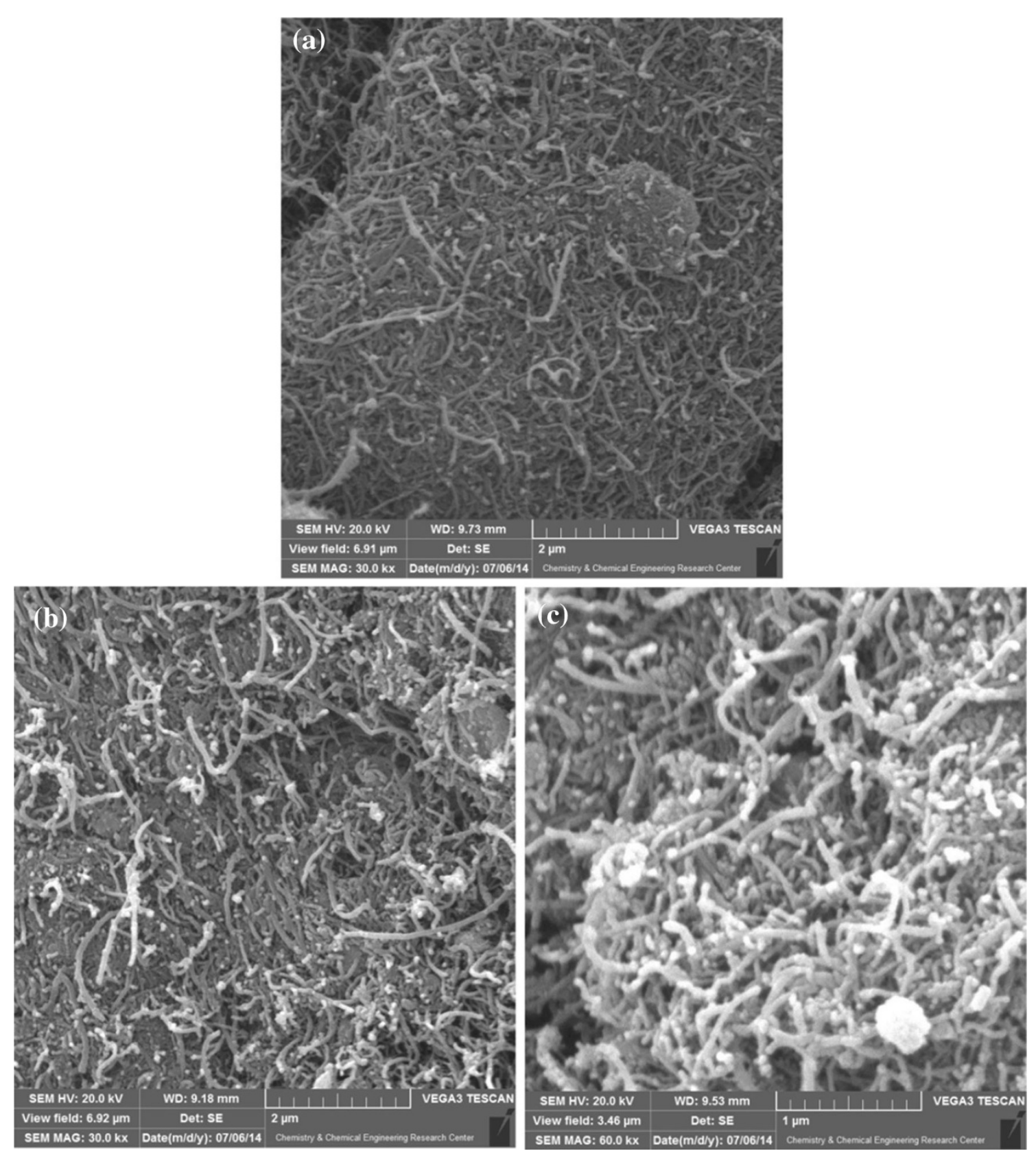

Fig. 5 SEM images of a the MWCNT-COOH, b, c MWCNT- $-\mathrm{Fe}_{3} \mathrm{O}_{4}$

the temperature range of $635-730{ }^{\circ} \mathrm{C}$ is caused by the oxidization of the nanotubes [17]. Compared with the pristine MWCNTs, the MWCNT- $\mathrm{Fe}_{3} \mathrm{O}_{4}$ composites lost their weight at a lower temperature range of $490-635^{\circ} \mathrm{C}$ (Fig. 6b), leaving iron oxide residue weight of around $26.65 \%$ for $6 \mathrm{~nm} \mathrm{Fe}_{3} \mathrm{O}_{4} / \mathrm{MWCNT}$ a. This is attributed to the catalytic role of metal oxide nanoparticles in the oxidation of carbon materials [18].

\section{VSM analysis}

The magnetic property of the MWCNT- $\mathrm{Fe}_{3} \mathrm{O}_{4}$ nanocomposite was investigated by VSM. Figure 7 shows the magnetization curves measured at $25^{\circ} \mathrm{C}$ for the sample fabricated at $200{ }^{\circ} \mathrm{C}$ for $12 \mathrm{~h}$. Magnetization increased with an increase in the magnetic field. MWCNT-COOH possessed good magnetic properties, although the 
Fig. 6 TGA curves of a MWCNTs, b 6 nm MWCNT$\mathrm{Fe}_{3} \mathrm{O}_{4}$ composite, and $\mathbf{c} \mathrm{Fe}_{3} \mathrm{O}_{4}$

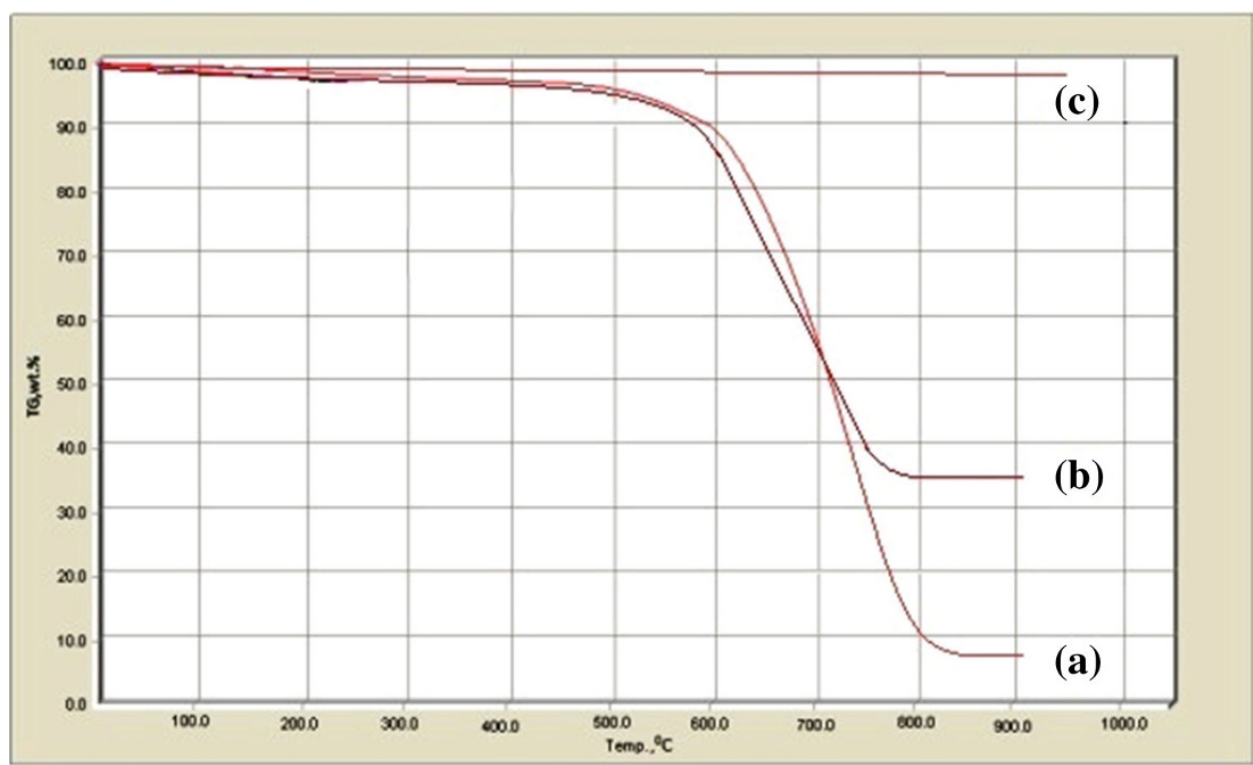

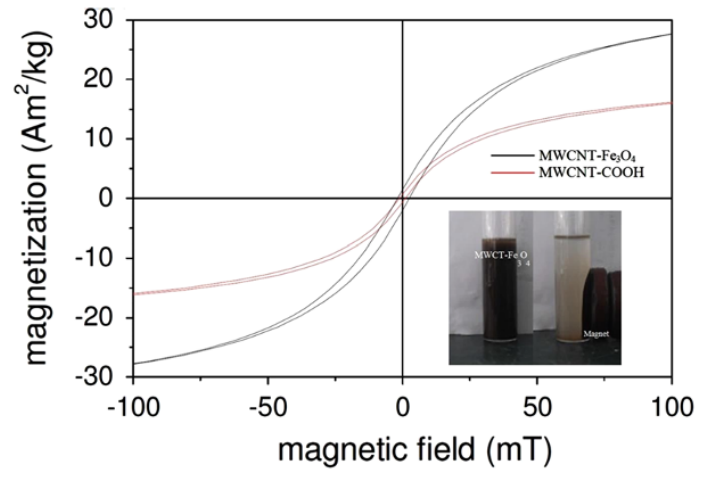

Fig. 7 Magnetization curves of MWCNT- $-\mathrm{Fe}_{3} \mathrm{O}_{4}$ composite and $\mathrm{MWCNT}-\mathrm{COOH}$ at room temperature

saturation magnetization was slightly lower than that of MWCNT- $-\mathrm{Fe}_{3} \mathrm{O}_{4}$. Both compounds exhibited an extremely small hysteresis loop and low coercivity, as typically characteristic of superparamagnetic particles [19]. It is worth mentioning, this analysis shows that the saturation magnetization of the magnetic MWCNT composites was different and is significantly higher at functionalized samples.

\section{Conclusions}

A simple, effective and reproducible method has been carried out for synthesizing $\mathrm{MWCNT}-\mathrm{Fe}_{3} \mathrm{O}_{4}$ magnetic nanocomposites. Magnetic measurements proved that MWCNT- $\mathrm{Fe}_{3} \mathrm{O}_{4}$ composite had superparamagnetic characteristics at room temperature. This study would help to develop a new composite material with excellent properties employed in large-scale fabrication of magnetic CNT hybrid materials.

Acknowledgments HS, RS and MK would like to thank Islamic Azad University for all supports.

Open Access This article is distributed under the terms of the Creative Commons Attribution License which permits any use, distribution, and reproduction in any medium, provided the original author(s) and the source are credited.

\section{References}

1. Iijima, S.: Helical microtubules of graphitic carbon. Nature 354(6348), 56-58 (1991)

2. Ouyang, M., Huang, J.L., Lieber, C.M.: One-dimensional energy dispersion of single-walled carbon nanotubes by resonant electron scattering. Phys. Rev. Lett. 88(6), 066804 (2002)

3. Thostenson, E.T., Ren, Z.F., Chou, T.W.: Advances in the science and technology of carbon nanotubes and their composites: a review. Comp. Scien. Tech. 61(13), 1899-1912 (2001)

4. Bahr, J.L., Mickelson, E.T., Bronikowski, M.J., Smalley, R.E., Tour, J.M.: Dissolution of small diameter single-wall carbon nanotubes in organic solvents? Chem. Commun. 2, 193-194 (2001)

5. Singh, S., Barick, K.C., Bahadur, D.: Functional oxide nanomaterials and nanocomposites for the removal of heavy metals and dyes. Environment 4, 5 (2013)

6. Giersig, M., Hilgendorff, M.: Magnetic nanoparticle superstructures. Eur. J. Inorg. Chem. 18, 3571-3583 (2005)

7. Kanagesan, S., Hashim, M., Tamilselvan, S., Alitheen, N. B., Ismail, I., Hajalilou, A., Ahsanul, K.: Synthesis, characterization, and cytotoxicity of iron oxide nanoparticles. Adv. Mater. Sci. Eng. 2013 (2013)

8. Chen, W., Pan, X., Bao, X.: Tuning of redox properties of iron and iron oxides via encapsulation within carbon nanotubes. J. Am. Chem. Soc. 129(23), 7421-7426 (2007) 
9. Fan, X.J., Li, X.: Preparation and magnetic properties of multiwalled carbon nanotubes decorated $\mathrm{Fe}_{3} \mathrm{O}_{4}$ nanoparticles. Carbon 50(10), 3962 (2012)

10. He, F., Fan, J., Ma, D., Zhang, L., Leung, C., Chan, H.L.: The attachment of $\mathrm{Fe}_{3} \mathrm{O}_{4}$ nanoparticles to graphene oxide by covalent bonding. Carbon 48(11), 3139-3144 (2010)

11. Gupta, V.K., Agarwal, S., Saleh, T.A.: Chromium removal by combining the magnetic properties of iron oxide with adsorption properties of carbon nanotubes. Water Res. 45(6), 2207-2212 (2011)

12. Jishi, R.A., Venkataraman, L., Dresselhaus, M.S., Dresselhaus, G.: Phonon modes in carbon nanotubules. Chem. Phys. Lett. 209(1), 77-82 (1993)

13. Fan, X.J., Li, X.: Preparation and magnetic property of multiwalled carbon nanotubes decorated by $\mathrm{Fe}_{3} \mathrm{O}_{4}$ nanoparticles. New Carbon Mater. 27(2), 111-116 (2012)

14. Chang, P.R., Zheng, P., Liu, B., Anderson, D.P., Yu, J., Ma, X.: Characterization of magnetic soluble starch-functionalized carbon nanotubes and its application for the adsorption of the dyes. J. Hazard. Mater. 186(2), 2144-2150 (2011)
15. Yao, Z., Braidy, N., Botton, G.A., Adronov, A.: Polymerization from the surface of single-walled carbon nanotubes-preparation and characterization of nanocomposites. J. Am. Chem. Soc. 125(51), 16015-16024 (2003)

16. Perales Perez, O., Umetsu, Y., Sasaki, H.: Precipitation and densification of magnetic iron compounds from aqueous solutions at room temperature. Hydrometallurgy 50(3), 223-242 (1998)

17. Zhang, M., Yudasaka, M., Bandow, S., Iijima, S.: Thermogravimetric analysis for the array of $\mathrm{C}_{60}$ molecules formed in single-wall carbon nanotube. Chem. Phys. Lett. 369(5), 680-683 (2003)

18. Li, J., Tang, S., Lu, L., Zeng, H.C.: Preparation of nanocomposites of metals, metal oxides, and carbon nanotubes via selfassembly. J. Am. Chem. Soc. 129(30), 9401-9409 (2007)

19. Liu, S., Zhang, L., Zhou, J., Xiang, J., Sun, J., Guan, J.: Fiberlike $\mathrm{Fe}_{2} \mathrm{O}_{3}$ macroporous nanomaterials fabricated by calcinating regenerate cellulose composite fibers. Chem. Mater. 20(11), 3623-3628 (2008) 